\title{
Degradation profile and safety evaluation of methomyl residues in tomato and soil
}

\author{
F. Malhat ${ }^{1,2,}$, H. Watanabe ${ }^{2}$ and A. Youssef ${ }^{3}$
}

Summary A high performance liquid chromatography with the photodiode array detector (HPLCDAD) analytical method was developed to determine the residue levels and investigate the dissipation pattern and safety use of methomyl in tomato and soil. Methomyl residues were extracted from tomato and soil samples with ethyl acetate. The extract was cleaned up with the QuEChERS method. The results showed that the average recoveries were in the range of $87.1-94.5 \%$, with RSD of $6.9-11.2 \%$. Limits of detection (LOD) and quantification (LOQ) were 0.005 and $0.007 \mathrm{mg} / \mathrm{kg}$, respectively. The residue levels of methomyl were best described to first order rate kinetics and half-lives ranged from 1.34 to 1.8 days in tomato and soil, respectively. The theoretical maximum residue contributions for methomyl on tomato were found to be less than the maximum permissible intake values even on zero days, therefore consumer health risks are minimal at the recommended dose on tomato.

Additional keywords: Dissipation, HPLC-DAD, QuEChERS method, Risk assessment

\section{Introduction}

Tomato, Solanum Lycopersicum L. (Solanaceae), is grown throughout the globe and its berry (fruit) constitutes an important part of human diet (Gupta et al., 2011). In Egypt, tomato is cultivated in about 221 thousand hectares which represent about 34 $\%$ of the average area of vegetables, while the fruits are basic component of the daily diet (Malhat et al., 2012a). Chemical pesticides are often applied for plant protection of the crop (Singh et al., 1980; 1989; Awasthi, 1986). Nearly all these chemicals are readily soluble in plant oils and waxes (Ripley and Edgington 1983; Malhat and Hassan, 2011), pausing an urgent need for monitoring programs of pesticide residues to properly assess the relevant human exposure and environmental risks.

Pesticide dissipation rate after application is a useful gauge for the assessment of

\footnotetext{
1 Pesticide Residues and Environmental Pollution Department, Central Agricultural Pesticide Laboratory, Agriculture Research Center, Dokki, Giza, 12618, Egypt

2 Tokyo University of Agricultural and Technology, 3-58 Saiwaicho, Fuchu, Tokyo 183-8581, Japan

3 Packing and Packaging Materials Department, National Research Center, Dokki, Cairo, Egypt

* Corresponding author:farag_malhat@yahoo.com
}

residue levels trend (Malhat et al., 2015). Residue dissipation curves can be used to estimate the time required for residues to reach levels below maximum residue limits (MRLs) (Fong et al., 1999; Malhat et al., 2014b). In addition, the MRL regulations require a preharvest interval (PHI) to ensure that dissipation of a pesticide is below the proposed $M R L$ at harvest time. The determination of pesticide residues is usually accomplished by chromatographic techniques and involves many preliminary steps like extraction and clean-up for interference removal.

An adequate description of pesticide degradation in soil is important for the risk assessments within the pesticide registration process. The fate of the pesticides in the soil environment in respect of pest control efficacy, non-target organism exposure and offsite mobility has become a matter of environmental concern (Hafez and Thiemann, 2003) potentially because of the adverse effects of pesticidal chemicals on soil microorganisms (Araújo et al., 2003), which in turn may affect soil fertility (Schuster and Schröder, 1990). Several factors influence the final concentration of the pesticide in soil including volatilization, photochemical degradation, chemical and biological transformation, leaching and sorption (Malhat et 
al., 2013; Purnama et al., 2015).

Methomyl (5-methyl-N-(methyl carbamoyloxy) thioacetimidate) (Figure 1) has ovicidal, larvicidal and adultcidal action against a variety of insect crop pests as well as an acaricidal effect (Chakraborty and Pahari, 2002; Furness, 2005). Different extraction and quantification methods including HPLC-DAD are used by various scientists for estimation of methomyl residues in several vegetables and fruits (Alawi and Rüssel, 1981; Steven and Lin, 1992). The main criteria for opting any methodology is that analytical method should be fast, easy, inexpensive and applicable to different matrices. Currently, there are no reports in the literature of the analysis of methomyl in tomato and soil using the QuEChERS method coupled with liquid chromatography with a photodiode array detector.

In this study, we set up and validate a modified QuEChERS method followed by HPLC-DAD for quantifying methomyl residues in tomato and soil. Supervised field trials were conducted to determine the dissipation kinetics in tomato and soil. From the generated data, the pre-harvest interval (PHI) was established based upon the dissipation pattern as well as the biological half-life. Furthermore, it is rather imperative to ascertain the food safety hazard by evaluating residues of methomyl in terms of their dietary exposure related to the acceptable daily intake (ADI) and maximum permissible intake (MPI).

\section{Materials and Methods}

\section{Chemical and Reagents}

The certified reference standard of methomyl was provided from central agri-

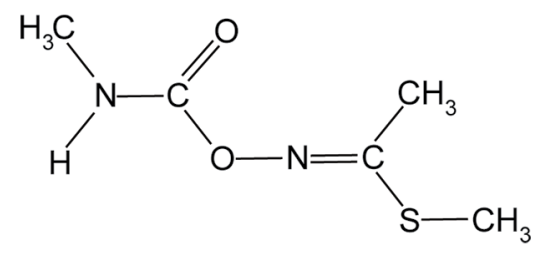

Figure 1. Chemical structure of methomyl cultural pesticide laboratory, Egypt, and was of $>99 \%$ purity. All organic solvents were of HPLC grade and were purchased from Merck. Primary secondary amine (PSA, $40 \mu \mathrm{m}$ Bondesil) and graphite carbon black (GCB) sorbents were purchased from Supelco (Supelco, Bellefonte, USA). Analytical grade anhydrous sodium sulfate was purchased from El Naser pharmaceutical chemical Co. (Cairo, Egypt); it was activated by heating at $250^{\circ} \mathrm{C}$ for $4 \mathrm{~h}$ in the muffle furnace, cooled and kept in desiccators before use.

\section{Preparation of standard solution}

The stock standard solution ( $\left.100 \mathrm{mg} \mathrm{L}^{-1}\right)$ of methomyl was prepared in methanol and subsequently stored at $-18^{\circ} \mathrm{C}$. An intermediate solution (10 $\left.\mathrm{mg} \mathrm{L}^{-1}\right)$ was prepared by appropriate dilution with methanol. The calibration standards (five calibration points) ranging from 0.005 to $1.0 \mathrm{mg} \mathrm{L}^{-1}(0.005,0.01,0.05,0.1$ and $1.0 \mathrm{mg} \mathrm{L}^{-1}$ ) were prepared by successive dilution of the intermediate working standard with pure solvent and matrix extract. All standard solutions were stored at $-18^{\circ} \mathrm{C}$ in amber glass bottles until further analysis.

\section{Instrument and apparatus}

The food processor was a Thermomix, Vorwerk. The rotary evaporator was Butch. The HPLC analysis was performed with an Agilent 1260 HPLC system, with quaternary pump, autosampler injector, thermostat compartment for the column and photodiode array detector.

\section{Field experiment}

Field experiments were conducted at ElHakimayia village, Miet-Gamer Province, ElDkahlyia Governorate, Egypt. The field trail for methomyl was conducted with one commercially available soluble powder formulation (Lannate 90\% SP). One treatment was carried out on 2 August 2011 at the maximum recommended dose ( 675 g.a.i.ha ${ }^{-1}$ ). The treatments, including the untreated control, were replicated three times in a complete randomized block design. The average maximum and minimum temperature during the experiment were $25^{\circ} \mathrm{C}$ and $39^{\circ} \mathrm{C}$. There 
was no rainfall during the experiment.

\section{Sampling procedures and storage}

Samples of pre marked tomato fruits of the same ripening stage and size were harvested at random from each replicate of the treated and control plots separately at regular time intervals on 0 ( 2 hour after spraying), $1,2,4,7,10,13$, and 17 days after methomyl application. Soil samples were collected at the same times with the tomato samples, by obtaining a $2 \mathrm{~kg}$ of soil for each replicate. Immediately after collecting, samples were transported at $4^{\circ} \mathrm{C}$ and in darkness in labelled polyethylene bags to the laboratory, where they were processed. The tomatoes were homogenised in a food processor and the homogenate of each sample was placed in polyethylene containers and frozen at -18 ${ }^{\circ} \mathrm{C}$ until analysis. Soil samples were air-dried at $20^{\circ} \mathrm{C}$, sieved to obtain sub-samples and were placed in polyethylene bags and frozen at $-18^{\circ} \mathrm{C}$ until analysis.

\section{Extraction and clean up}

A sub-sample of $10 \mathrm{~g}$ was extracted from each tomato or soil sample with $10 \mathrm{ml}$ eth$\mathrm{yl}$ acetate in the presence of $10 \mathrm{~g}$ anhydrous sodium sulphate by homogenization followed by centrifugation at $3800 \mathrm{rpm}$ for $10 \mathrm{~min}$. An aliquot of $4 \mathrm{ml}$ of the supernatant was drowning in a $15 \mathrm{ml}$ polypropylene tube containing $100 \mathrm{mg}$ of the cleanup agent PSA and $20 \mathrm{mg} \mathrm{GCB}$. The mixture was shaken vigorously and centrifuged at $3800 \mathrm{rpm}$ for $5 \mathrm{~min}$. $2 \mathrm{ml}$ of the supernatant was taken, evaporated to dryness, the residue was re-dissolved in $2 \mathrm{ml}$ of methanol, filtered through a $0.2 \mu \mathrm{m}$ PTFE syringe filter and then directly measured by HPLC-DAD.

\section{HPLC analysis}

Final analysis of methomyl residues was done by HPLC. The chromatographic column was $C_{18}$ Zorbax XDE (250 mm x $4.6 \mathrm{~mm}$, $5 \mu \mathrm{m}$ film thickness). The column was kept at room temperature. Flow rate of mobile phase $($ methanol/water $=90 / 10 \mathrm{v} / \mathrm{v}$ ) was 1 $\mathrm{ml} / \mathrm{min}$, and injection volume was $20 \mu \mathrm{l}$. Detection wavelength for detection of meth- omyl was set at $254 \mathrm{~nm}$. The retention time of methomyl was $5.7 \mathrm{~min}$. The residues in the field incurred samples were tentatively identified by comparing the retention times (RTs) of the sample peaks with that of the injected standard. The chromatographic apparatus was controlled by Chemstation software.

\section{Method validation}

The recovery experiment were carried out on fresh untreated tomato and soil by fortifying the samples $(10 \mathrm{~g})$ with methom$\mathrm{yl}$ at three concentration levels (i.e. LOQ, 5 $x$ LOQ and 25 x LOQ). The fortified samples were processed as previously described and analyzed by HPLC to evaluate the accuracy and the precision of the analytical procedure. Recovery test was replicated five times for each fortification level. The calibration curve for methomyl was obtained by plotting the peak area against the concentration of the corresponding calibration standard. The limit of detection (LOD) of methomyl was determined as the lowest concentration giving response of three times the standard deviation of the base line noise defined from the analysis of three control samples. The limit of quantification (LOQ) was determined as the lowest concentration of a given response that could be quantified with relative standard deviation lower than $20 \%$.

\section{Statistical Analysis}

The dissipation kinetics of methomyl in tomato and soil were determined by plotting the residue concentration against time and the maximum squares of correlation coefficient found were used to determine the equations of best fit curves. For all the samples studied, exponential relationships were found to apply, corresponding to the first order rate equation. Confirmation of the first order kinetics was further made graphically from the equation of $C_{t}=C_{0} e^{-k t,}$ where $C t$ represents the concentration of the pesticide residue at the time of $t, C_{0}$ represents the initial deposits after application and $k$ is the degradation rate constant in days ${ }^{-1}$. The half-life $\left(t_{1 / 2}\right)$ was calculated from the $\mathrm{k}$ value for each experiment, being $t_{1 / 2}=\ln 2 / \mathrm{k}$. 


\section{Results and Discussion}

\section{Matrix effects and linearity}

The matrix effect of the present method was investigated by comparing the relative responses of standards in solvent with matrix-matched standards for 5 replicates at $0.5 \mathrm{mg} \mathrm{L}^{-1}$. The relative responses (response matrix/response solvent) were 1.01 and 1.04 for tomatoes and soil, respectively. It can be concluded that the matrix doesn't significantly suppress or enhance the response of the instrument. The results showed that no interfering endogenous peak appeared, and the retention times of the tested analyte at the spiked sample completely matched those of the standard samples. Good linearity was obtained over the concentration ranges $\left(0.005,-1.0 \mu \mathrm{g} \mathrm{mL}^{-1}\right)$ with $R^{2}>0.999$, under this condition.

\section{Method performance}

The analytical method was developed as to provide a rapid accurate and efficient means of determining methomyl residues in tomatoes and soil. Table 1 shows the fortified results of methomyl in tomato and soil samples. The mean recoveries in tomato samples for methomyl were $87.1-94.5 \%$, with RSD of $6.9-11.2 \%$. Recovery rates and their relative standard deviation were acceptable. The LOQs and LODs were found to be $0.007 \mathrm{mg}$ $\mathrm{kg}^{-1}$ and $0.005 \mathrm{mg} \mathrm{kg}^{-1}$, respectively, ensuring $\mathrm{LOQ}$ values significantly lower than the MRLs $(0.02 \mathrm{mg} / \mathrm{kg})$ established by the European Union. These results demonstrate the good performance of the method according to document SANCO/12571/2013 (SANCO, 2013).

Table 1. Fortification level and recovery percentage ( \pm RSD) of methomyl in tomato and soil samples.

\begin{tabular}{l|c|c}
\hline \multirow{2}{*}{$\begin{array}{l}\text { Fortification levels } \\
(\mathrm{mg} / \mathrm{kg})\left(\mathrm{n}^{*}=5\right)\end{array}$} & \multicolumn{2}{|c}{ Methomyl } \\
\cline { 2 - 3 } & Tomato & Soil \\
\hline 0.006 & $87.10 \pm 8.4$ & $92.5 \pm 5.2$ \\
0.03 & $94.5 \pm 11.2$ & $90.9 \pm 12.6$ \\
0.15 & $92.1 \pm 6.9$ & $88.3 \pm 13$ \\
\hline
\end{tabular}

* number of replicates

\section{Dissipation behaviour in tomato}

Mean residue levels of methomyl during the sampling period for the recommended application dose derived from the extraction and analysis of three tomato sub samples are shown in Figure 2 and Table 2. The results showed that methomyl residues were easy to be decomposed. The original deposits of methomyl at the recommended dosage were $1.272 \mathrm{mg} / \mathrm{kg}$. These deposits dissipated to $0.007 \mathrm{mg} / \mathrm{kg} 10$ days after methomyl application, thereby, showing a loss of $99.44 \%$. The residues of methomyl in tomato reached below the LOQ of $0.006 \mathrm{mg} / \mathrm{kg}$ in 13 days after application at the recommended dosage. The dissipation curve of methomyl in tomatoes is presented in Figure 1. Degradation equation of methomyl in tomato is as follows: $C_{t}=1.412^{-0.517 t}$ (methomyl). Estimated half-life of methomyl was 1.34 days. A similar $t_{1 / 2}$ to that found in our results was observed in a study of the dissipation rate of methomyl in cabbage and tomato (Othman et al., 1987), although studies made in grape showed a higher $t_{1 / 2}$ than ours (Kaushik et al., 2006). Different species, weather conditions, the physical and chemical properties of pesticides, method and rate of application may be responsible for the different dissipation rates of this compound (Romeh and Mekky, 2009; Malhat et al., 2012b, 2014c). In the field, besides the effect of some physical and chemical factors such as light, heat, $\mathrm{pH}$ and moisture (Agnihothrudu and Muraleedharan, 1990; Chen et al., 1987; Cosby et al., 1972; Miller and Donaldson, 1994; Malhat, 2012) on the degradation of pesticides, growth dilution factor might play a significant role in the degradation of methomyl residues (Agnihothrudu and Muraleedharan, 1990; Bisen and Ghosh Hajara, 2000; Chen and Wan, 1988; Khay et al., 2008; Cabras et al., 1990, Malhat, 2013).

\section{Dissipation behaviour in soil}

Figure 2 shows the decline curve of methomyl in soil. The dissipation dynamics of methomyl can be described by the following first-order kinetics equation $C_{t}=1.404^{-0.386 t}$ $\left(R^{2}=0.992\right)$. The $t_{1 / 2}$ for methomyl in soil was 


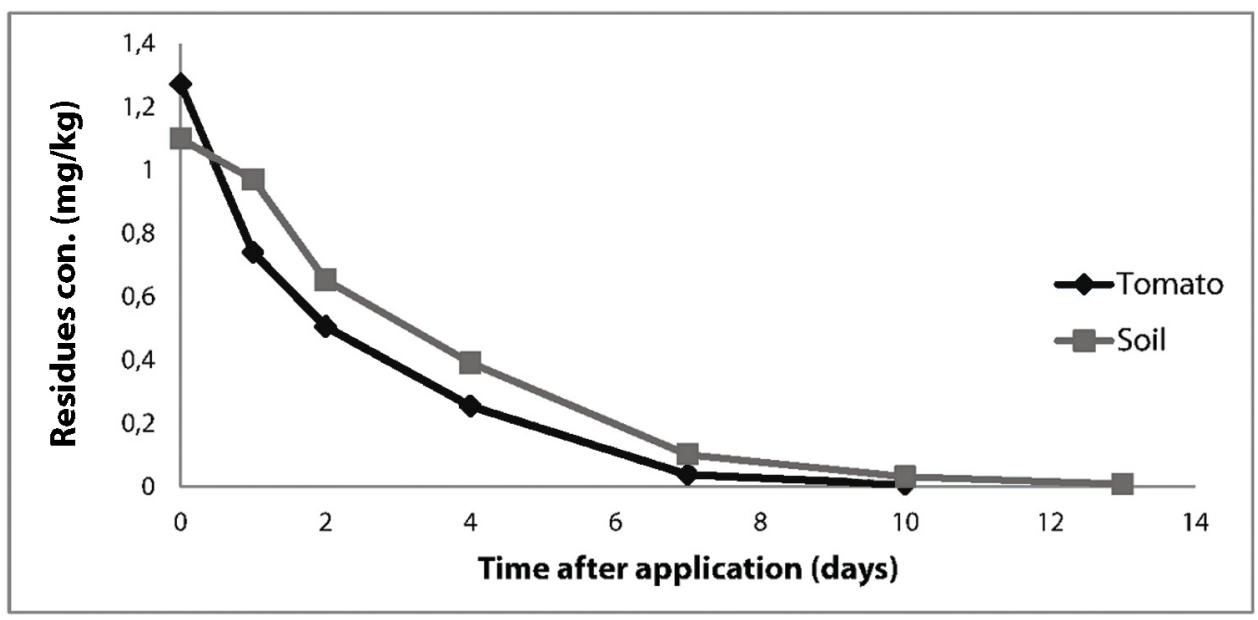

Figure 2. Dissipation pattern of methomyl in tomato and soil at the recommended dosage of application.

Table 2. Residue levels ( $\mathrm{mg} / \mathrm{kg} \pm \mathrm{SD}$ ) of methomyl in tomatoes and soil after application.

\begin{tabular}{l|c|c}
\hline \multirow{2}{*}{ Time (days) } & \multicolumn{2}{|c}{ Residues $(\mathrm{mg} / \mathrm{kg}) \pm \mathrm{SD}^{*}$} \\
\cline { 2 - 3 } & Tomatoes & Soil \\
\hline 0 & $1.272 \pm 0.10$ & $1.100 \pm 0.30$ \\
1 & $0.740 \pm 0.11$ & $0.971 \pm 0.10$ \\
2 & $0.506 \pm 0.08$ & $0.653 \pm 0.09$ \\
4 & $0.254 \pm 0.07$ & $0.391 \pm 0.05$ \\
7 & $0.038 \pm 0.01$ & $0.101 \pm 0.03$ \\
10 & $0.007 \pm 0.01$ & $0.031 \pm 0.01$ \\
13 & - & $0.008 \pm 0.005$ \\
17 & - & - \\
\hline
\end{tabular}

* Three replicates

1.8 days. The results showed that the dissipation was also fast in the soil. A decline in soil residues may be attributed primarily to growth dilution between application and sampling, as well as to volatilization which occurs during the first few days following application. Other parameters involve sorpation-desorpation, chemical and biological degradation, uptake by plants, run-off and leaching (Fang and Qiu 2002; Spunu, 1989; Malhat and Hassan, 2011).

The results showed that the tested pesticides had a higher degradation in tomato fruits compared with soil, which could be attributed to the high growth rate of fruits which causes a dilution of pesticides. In addition, tomatoes were exposed to various factors, including direct sunlight and daily temperature that affected degradation rates of pesticides.

\section{Risk assessment of methomyl}

The risk to the consumer from methom$\mathrm{yl}$ on tomatoes has been evaluated by comparing Theoretical Maximum Residue Contribution (TMRC) of the pesticide with its Maximum permissible Intake (MPI). The acceptable daily intake (ADI) for methomyl has been observed to be $0.02 \mathrm{mg} / \mathrm{kg}$ body weight per day (Tomlin, 2009). The maximum permissible intake (MPI) was obtained by multiplying the ADI with the average body weight of an adult taken as $60 \mathrm{~kg}$ (Malhat et al., 2014-a, Loutfy et al., 2015). MPI was calculated to be $1.2 \mathrm{mg} /$ person/day without any appreciable life risk. The TMRC has been calculated by multiplying the maximum residue levels with average per capita daily consumption of $77 \mathrm{~g}$ of total vegetables in Egyptian context (WHO, 2003). The TMRC values on 0 day are found to be $0.098 \mathrm{mg} /$ person/day (Table 3). As the TMRC for methomyl on tomatoes are found to be less than the toxicological estimated MPI value of 1.2 $\mathrm{mg} /$ person/day, even on 0 day, the consum- 
Table 3. Theoretical maximum residue contribution (TMRC) and maximum permissible intake (MPI) of methomyl in tomatoes.

\begin{tabular}{|c|c|c|c|c|c|c|c|c|c|c|}
\hline \multirow{2}{*}{$\begin{array}{l}\text { Pesticide } \\
\text { name }\end{array}$} & \multirow{2}{*}{$\begin{array}{c}\text { Dose } \\
\left(\mathrm{kg} \text { a.i. } \mathrm{ha}^{-1}\right)\end{array}$} & \multirow{2}{*}{$\begin{array}{c}\text { ADI } \\
\text { (mg kg b.w) }\end{array}$} & \multirow{2}{*}{$\begin{array}{c}\text { MPI } \\
\text { (mg/per- } \\
\text { son/day) }\end{array}$} & \multicolumn{7}{|c|}{ TMRC (mg/person/day) } \\
\hline & & & & 0 day & 1 day & 2 days & 4 days & 7 days & 10 days & 13 days \\
\hline Methomyl & 0.675 & 0.020 & 1.2 & 0.098 & 0.057 & 0.039 & 0.020 & 0.003 & 0.0006 & - \\
\hline
\end{tabular}

er health risks are minimal at recommended dose on tomatoes.

In this study, the dissipation dynamic and risk assessment of methomyl were investigated in tomatoes under field conditions to determine consumer safety. A relative simple and fast method was developed to analyze the residue of methomyl in tomatoes fruit and soil. The residue of methomyl dissipated following first order kinetics. The results of this study are expected to help establish the safe and proper use of methom$y l$ in tomatoes crop grown under field conditions in Egypt.

Part of this work was funded by the Japanese Society for the Promotion of Science (JSPS) operating grant (26.04074) provided as Postdoctoral Fellowship for Foreign Researchers to the first author. The authors are grateful to all the stuff in Central Agricultural Pesticide Laboratory (Egypt) for their technical support.

\section{Literature cited}

Agnihothrudu, V. and Muraleedharan, N. 1990. Pesticide residues in tea. Planter's Chronicle 85: 125127

Alawi M. and Rüssel, H. 1981. Determination of methomyl and methomyl-oxime in fruit crops and water by HPLC. Fresenius' Zeitschrift für Analytische Chemie, 309: 8 - 12.

Araujo. A.S.F., Monteiro, R.T.R and Abarkeli, R.B. 2003. Effect of glyphosate on the microbial activity of two Brazilian soils. Chemosphere, 52: 799-804.

Awasthi, M.D. 1986. Residues of pyrethroid treatments, alone or with foliar urea, on tomato. Phytoparasitica, 14(3): 231-233.

Bisen, J.S. and Ghosh Hajara, N. 2000. Persistence and degradation of some insecticides in Darjeeling tea. Journal of Plantation Crops, 28(2): 123-131.
Cabras P., Angioni A., Garau, V., Minelli, E., Cabitza, F. and Cubeddu, M., 1997. Residues of some pesticides in fresh and dried apricots. Journal of Agricultural and Food Chemistry, 45: 3221-3222.

Cabras, P., Spanedda, L., Cabitza, F., Cubeddu, M., Martini, M., Brandolini, G. 1990. Pirimicarb and its metabolites residues in lettuce. Influence of cultural environment. Journal of Agricultural and Food Chemistry, 38(3): 879-882.

Chakraborty S. and Pahari A. 2002. Studies on the control of important pests of okra by Lannate 40SP. Pesticide Research Journal, 14:100-106.

Chen, Z.M and Wan H.B. 1988. Factors affecting residues of pesticides in tea. Pesticide Science, 23: 109-118.

Chen, Z.M, Wan, H.B, Wang, Y., Xue, Y. and Xia, H. 1987. Fate of pesticides in the ecosystem of tea garden. In Proceedings of the international symposium, tea quality-human health, Hangzhou, China. Tea Research Institute, Chinese Academy of Agriculture Sciences, November 4-9, p. 146-149.

Cosby, P.G, Moilanon, K.W., Nakagawa M. and Wong, A.S. 1972. Environmental Toxicology of Pesticides. New York: Academic Press, p. 423.

Fang, H, Qiu, L. 2002. Research of the behaviour of pesticide in soil environment. Soil and Environmental Sciences, 11: 94-97.

Fong, W.G., Moye, H.A., Seiber, J.N. and Toth, J.P. 1999. Pesticide Residues in Foods, Methods, Techniques and Regulations. John Wiley and Sons, New York, NY, USA, p. 63-74.

Furness, G. 2005. Chemical and integrated control of long tailed mealybug Pseudococcus Longispinus (Targioni-Tozzetti) (Hemiptera: Coccidae) in the riverland of South Australia. Australian Journal of Agricultural Research, 28:319-332.

Gupta, S., Gajbhiye, V., Sharma, R. and Gupta, R. 2011. Dissipation of cypermetherin, chlorpyriphos, and profenofos in tomato fruits and soil following application of pre-mix formulations. Environmental Monitoring and Assessment, 174: 337-345.

Hafez, H.F.H. and Thiemann, W.H.P. 2003. Persistence and biodegradation of diazinone and imidacloprid in soil. Proceedings of the XII Symposium Pest Chemica Congress, (PCC'03), Centre Universita Cattolica, Piacenza, p. 35-42.

Kaushik, B., Ajay, K., Pandurang, G., Sangram, H., 
Dasharath, P. and Deepak R. 2006. Rate of degradation of $\gamma$-cyhalothrin and methomyl in grapes (Vitis vinifera L.). Food Additives and Contaminants, 23 (10): 994-999.

Khay, S., Choi. J. and Abd El-Aty, M. 2008. Dissipation behavior of lufenuron, benzoyphenylurea insecticide, in/on Chines cabbage applied by foliar spraying under greenhouse condition. Bulletin of Environmental Contamination and Toxicology, 81: 369-372.

Kumari, B., Madan, K., Singh, J., Singh, S. and Kathpal, T. 2004. Monitoring of pesticidal contamination of farm gate vegetables from Hissar. Environmental Monitoring and Assessment, 90: 1-3.

Loutfy, N., Malhat, F., Kamel, E. and Saber, A. 2015. Residual Pattern and Dietary Intake of Iprodione on Grapes under Egyptian Field Conditions, A Prelude to Risk Assessment Profile. International Journal of Human and Ecological Risk Assessment, 21(1): 265-279.

Malhat, F. 2012. Persistence of metalaxyl residues on tomato fruit using high performance liquid chromatography and QuEChERS methodology. Arabian Journal of Chemistry, http://dx.doi. org/10.1016/j.arabjc.2012.12.002.

Malhat, F. and Hassan, A. 2011. Level and Fate of Etoxazole in Green Bean (Phaseolus vulgaris). Bulletin of Environmental Contamination and Toxicology, 87 (2): 190-193.

Malhat, F. 2013. Simultaneous Determination of Spinetoram Residues in Tomato by High Performance Liquid Chromatography combined with QuEChERS method. Bulletin of Environmental Contamination and Toxicology, 90 (2): 222-226.

Malhat, F., Fayz, A., Loutfy, N. and Ahmed, M. 2013. Residues and dissipation of the pesticide emamectin benzoate under Egyptian field conditions: A case study. Toxicological and Environmental Chemistry, 95 (7): 1099-1107.

Malhat, F., Abdallah H. and Hegazy, I. 2012a. Dissipation of Chlorantraniliprole in Tomato Fruits and Soil. Bulletin of Environmental Contamination and Toxicology, 88 (3): 349-351.

Malhat, F., Abdallha, H., and Nasr, I. 2012b. Estimation of Etofenprox Residues in Tomato Fruits by QuEChERS Methodology and HPLC-DAD. Bulletin of Environmental Contamination and Toxicology, 88 (6): 891-893.

Malhat, F., El Sharkawi, H., Loutfy, N. and Tawfic Ahmed, M. 2014c. Field dissipation and Health hazard Assessment of Fenhexamid on Egyptian Grapes. Toxicological and Environmental Chemistry, 96 (5): 722-729.

Malhat, F., El-Mesallamy, A., Assy, M., Madian, W., Loutfy, N. and Ahmed, M. 2015a. Health Hazard Assessment of Pyridaben Residues in Egyptian Strawberries. Human and Ecological Risk Assessment, 21: 241-249.

Malhat, F., Loutfy, N. and Tawfic Ahmed, M. 2014b.
Dissipation Kinetics of Novaluron in Tomato: An Arid Ecosystem Pilot Study. Toxicological and Environmental Chemistry, 96(1): 41-47.

Malhat, F., Watanabe, H., Loutfy, N. and Tawfic Ahmed M. 2014a. Hazard assessment of the neonicotinoid insecticide thiamethoxam residues in tomato: a prelude to risk assessment profile. Toxicological and Environmental Chemistry, 96(2): 318-327.

Miller, G.C. and Donaldson, S.G. 1994. Factor affecting photolysis of organic compounds on soils. In G.R. Helz, R.G. Zepp and D.G. Crosby (eds.), Aquatic and surface photochemistry. Boca Raton, FL: Lewis Publishersn, p. 97-109.

Othman, M., Antonious, G.F., Khattab, M., Abdel-All, A. and Khamis, A. 1987. Residues of dimethioate and methomyl on tomato and cabbage in relation to their effect on quality-related properties. Environmental Toxicology and Chemistry, 6 (12): 947-952.

Purnama, I., Malhat, F., Jaikaew, P., Watanabe, H., Noegrohati, S., Rusdiarso, B. and Tawfic Ahmed, M. 2015. Degradation profile of azoxystrobin in Andisol soil: laboratory incubation, Toxicological and Environmental Chemistry, DOI: 10.1080/02772248.2015.1015297.

Ripley, B. and Edgington, L. 1983. International and external plant residues and relationships to activity of pesticides. Plant protection for human welfare, $10^{\text {th }}$. International congress of plant protection, Croydon England British Crop Protection Council, 2: 545-553

Romeh, A. and Mekky, M. 2009. Dissipation of profenofos, imidaclopride and penconazole in tomato fruits and products. Bulletin of Environmental Contamination and Toxicology, 83: 812-817.

SANCO/12571/2013. Guidance document on analytical quality control and validation procedures for pesticide residues analysis in food and feed. <http://www.eurl-pesticides.eu/library/docs/ allcrl/AqcGuidance_Sanco_2013_12571.pdf >.

Schuster, E. and Schroder, D. 1990. Side-effects of sequentially-applied pesticides on non-target soil microorganisms field experiments. Soil Biology and Biochemistry, 22: 367-373.

Singh, B, Dhaliwal, G, Kalra, R. 1980. Residues of quinqlphos and phosalone in tomato. Bulletin of Environmental Contamination and Toxicology, 24: 423-426.

Singh, B, Singh, P, Battu, R, Kalra, R. 1989. Residues of synthetic pyrethroid insecticides on tomato under sub-tropical condition of Punjab, India. Bulletin of Environmental Contamination and Toxicology, 43: 733-736.

Spynu, E. 1989. Predicting pesticide residues to reduce crop contamination. Reviews of Environment Contamination and Toxicology, 109: 89107.

Steven, C. and Lin, W. 1992. Determination of oxam- 
yl and methomyl by High-Performance Liquid Chromatography using a single-stage postcolumn derivatization reaction and fluorescence detection. Journal of Agricultural and Food Chemistry, 40: 1026-1029.

Tomlin, C.D.S. (ed.) 2009. The Pesticide Manual. British Crop Council. Surrey, U.K.
WHO, 2003. GEMS/food regional diets (regional per capita consumption of raw and semi-processed agricultural commodities). http://www.who.int/ foodsafety/publications/chem/regional_diets/ en.

Received: 8 April 2015; Accepted: 3 June 2015

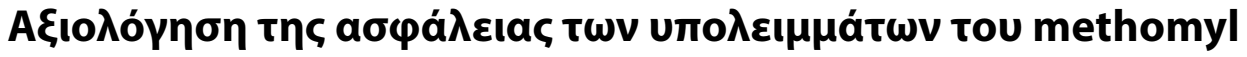

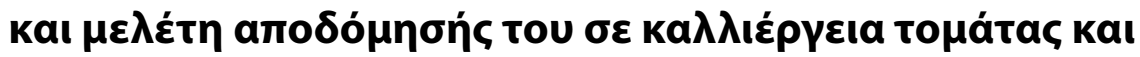

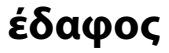

\author{
F. Malhat, H. Watanabe and A. Youssef
}

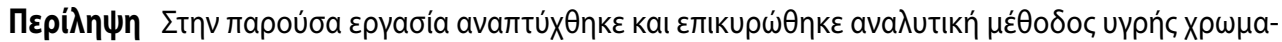

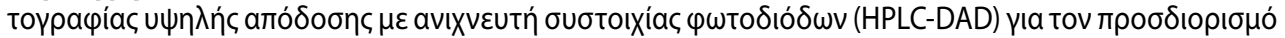

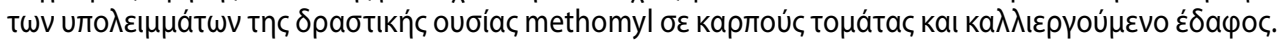

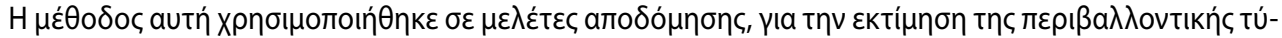

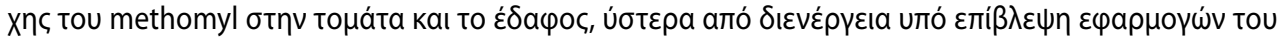

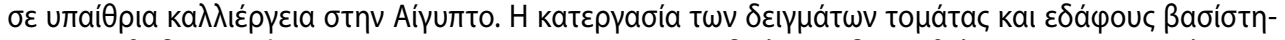

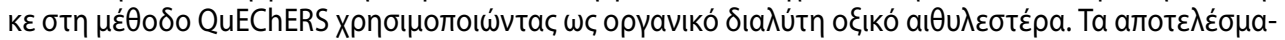

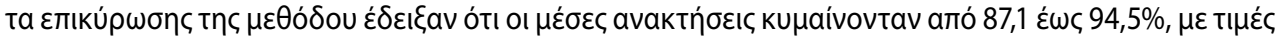

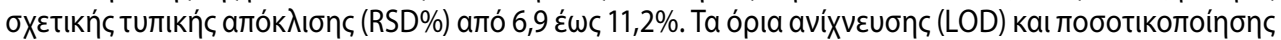

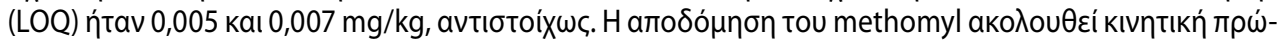

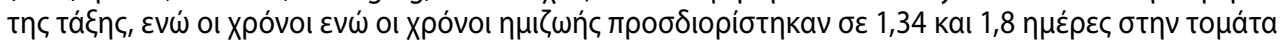

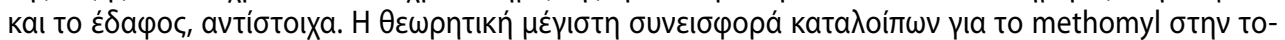

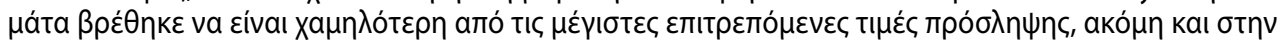

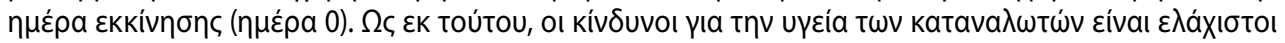

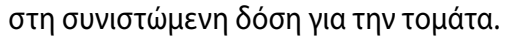

